\title{
Safety and Efficacy of Racotumomab-Alum Vaccine as Second-Line Therapy for Advanced Non-Small Cell Lung Cancer
}

\author{
Eduardo Santiesteban ${ }^{*}$, Leslie Perez ${ }^{2 *}$, Sailyn Alfonso ${ }^{3}$, Elia Neninger ${ }^{4}$, Soraida Acosta ${ }^{5}$, \\ Yoana Flores 6 , Maurenis Hernandez ${ }^{2}$, Carmen Viada ${ }^{2}$, Robin García ${ }^{4}$, Meylán Cepeda ${ }^{3}$, \\ Daymys Estevez², Yoisbel Moreno², Amparo Macías ${ }^{2}$ \\ ${ }^{1}$ José Ramón López Tabranes Hospital, Matanzas, Cuba \\ ${ }^{2}$ Center of Molecular Immunology, Havana, Cuba \\ ${ }^{3}$ Celestino Hernández Robau Hospital, Villa Clara, Cuba \\ ${ }^{4}$ Hermanos Ameijeiras Hospital, Havana, Cuba \\ ${ }^{5}$ Saturnino Lora Hospital, Santiago de Cuba, Cuba \\ ${ }^{6}$ National Institute of Oncology and Radiobiology, Havana, Cuba \\ Email: "leslie@cim.sld.cu
}

Received 23 May 2014; revised 22 June 2014; accepted 16 July 2014

Copyright (C) 2014 by authors and Scientific Research Publishing Inc.

This work is licensed under the Creative Commons Attribution International License (CC BY).

http://creativecommons.org/licenses/by/4.0/

(c) (i) Open Access

\section{Abstract}

Despite extensive clinical research in non-small cell lung cancer (NSCLC), overall survival is still poor. Racotumomab-alum is an anti-idiotypic cancer vaccine that targets NeuGcGM3 tumor associated ganglioside. The aim of this study was to evaluate safety and efficacy of racotumomab-alum in advanced NSCLC patients with progressive disease. This expanded access program included 86 histologically confirmed NSCLC patients, 18 years or older age, with advanced disease and without therapeutic option, with ECOG performance status $\leq 3$, adequate organ functions and signed informed consent. The primary endpoint was overall survival and toxicity was measure assessed treatment-related toxicity according CTCAEv3. The study was approved by ethical review boards of participant institutions. Racotumomab-alum treatment consisted in 5 biweekly intradermal doses $(1 \mathrm{mg} / \mathrm{mL})$ during the induction phase of treatment ( 2 months). The maintenance phase consisted in monthly re-immunizations until unacceptable toxicity or PS worsening. The median overall survival time of all patients treated with racotumomab-alum was 8.96 months. The survival rates at 12 and 24 months were $42.8 \%$ and $28.0 \%$, respectively. Patients that completed the induction phase of treatment (five doses or more) reached a median oS of 12.1 months. The most common adverse events were injection site reaction, bone pain, cough and asthenia. Racotumomabalum cancer vaccine could be considered an effective and safe treatment option as second-line

\footnotetext{
*First share authorship.

${ }^{\#}$ Corresponding author.
}

How to cite this paper: Santiesteban, E., et al. (2014) Safety and Efficacy of Racotumomab-Alum Vaccine as Second-Line Therapy for Advanced Non-Small Cell Lung Cancer. International Journal of Clinical Medicine, 5, 844-850. 
therapy for advanced NSCLC. Further clinical studies should be conducted to confirm this result.

Keywords

Non-Small Cell Lung Cancer, Cancer Vaccine, Second-Line Treatment

\section{Introduction}

Lung cancer is still the leading cause of cancer death worldwide. About 228,190 new cases and 160,000 deaths were estimated in United States for 2013 [1]. In Cuba, lung cancer is the first cause of death by cancer and 5097 deaths were reported in 2012 due to this. The mortality rate for lung cancer was 58.0 in men and 32.5 in women (per 100,000 habitants) in 2012 [2]. The incidence rate of lung cancer in 2009 for males was 42.2/100,000 population; while in females was 18.5/100,000 per habitants [2].

There are two major types of lung cancer according its biology, therapy and prognosis: non-small cell lung cancer (NSCLC) and small cell lung cancer. NSCLC represents more than $85 \%$ of all lung cancer diagnosis with adenocarcinoma subtype leading this subgroup. Common symptoms of lung cancer are cough, dyspnea, weight loss and chest pain. An early detection of this disease can decrease the mortality rate and improve patients' outcomes. Some prognostic factors are predictive of survival: early-stage at diagnosis, female gender, good performance status and no significant weight loss [3].

Despite the wide clinical research in the last years, only 15.9\% of lung cancer patients are alive 5 years or more after diagnosis [4]. Platinum-based doublet chemotherapy is still considered the best choice as front-line treatment and median overall survival time with these combinations is about of 8 to 11 months [5]. Several drugs have been approved for second-linetherapy: docetaxel, pemetrexed and erlotinib. In selected patients, these drugs produce response rates of $7 \%-15 \%$ and median survival time of 5 - 8 months [6]-[8]. A significant clinical benefit has been reported in terms of progression free survival (PFS) and overall survival (OS) with the introduction of maintenance strategies (continuation or switch maintenance) in non-progress or patients [9]. However, the subset of patients with progressive disease still has a poor prognosis and we need to identify new treatments in order to improve outcomes.

Immunotherapy has been identified as a useful strategy for cancer treatment. Several approaches have been tested with the aim of stimulating the immune system to develop an effective antitumor response. Gangliosides, in particular NeuGcGM3 are attractive targets for cancer immunotherapy, since they are over expressed in tumoral cells but not in normal cells [10] [11]. A Japanese group has recently reported that NeuGc-containing gangliosides are expressed in more than $90 \%$ of NSCLC patients [12].

Racotumomab-alum is an anti-idiotype vaccine composed by a murine monoclonal antibody and alum as adjuvant. It is able to induce a specific immune response against NeuGcGM3 in vaccinated cancer patients [13]. Immunogenicity and efficacy of this vaccine have been tested in phase I clinical trials that included patients with melanoma, breast cancer and lung cancer (small and non-small cell lung cancer) [14]-[18]. Recently, a significant benefit was reported in terms of progression free survival and overall survival in a phase II/III clinical trial with 176 NSCLC patients treated with racotumomab-alum or placebo as switch maintenance therapy [19]. There are two ongoing phase III clinical trials with racotumomab-alum for advanced NSCLC: PROACTIVE (clinicaltrials.gov NCT01460472) and RANIDO (rpcec.sld.cu RPCEC00000179).

The objective of this article is to describe the safety and efficacy of racotumomab-alum cancer vaccine as second-line treatment for advanced NSCLC patients included in an expanded access program.

\section{Patients and Methods}

A total of 86 histologically confirmed NSCLC patients were included in a multicenter expanded access program with racotumomab-alum cancer vaccine as second-line treatment. Eligible patients were 18 years or older, with advanced NSCLC (6th edition AJCC staging system) and progressive disease without therapeutic alternative that signed the informed consent, with an Eastern Cooperative Oncology Group performance status (ECOG PS) $\leq 3$ and adequate renal, haematologic and hepatic functions. Were excluded patients that had received previously racotumomab-alum treatment, patient that were pregnant or breast-feeding, known history of severe allergic 
reactions or patients with uncontrolled chronic diseases.

Included patients received five biweekly intradermaldoses of racotumomab-alum vaccine $(1 \mathrm{mg} / \mathrm{mL})$ during the induction phase of treatment ( 2 months). The maintenance phase consisted in monthly re-immunizations until unacceptable toxicity or PS worsening. Treatment was administered beyond progressive disease. The primary endpoint of this study was overall survival.

In order to evaluate the efficacy, the overall survival (OS) was taken into account as a primary endpoint of response and secondary endpoint was the survival rate at 12 and 24 months. Survival curves were estimated by the Kaplan-Meier method. The median and mean of survival were also estimated. Groups of more than 5 doses and fewer than 5 doses were compared by Log rank test. We also evaluated treatment-related toxicity as a secondary endpoint. Adverse events (AE) were classified according Common Terminology Criteria for Adverse Events version 3 (CTCAEv3).

This study was approved by ethical review boards of each participant institutions and was conducted in compliance with Good Clinical Practice guidelines. All included patients provided written informed consent before enrollment.

\section{Results}

Between April 2008 and December 2009, 86 patients with advanced NSCLC were recruited in four Cuban hospitals. All of them were included in the intent to treat (ITT) efficacy analysis. Patient's baseline characteristics are shown in Table 1. The median age was 62.4 with a range from 41 to 81 years. There was a predominance of

\begin{tabular}{|c|c|c|}
\hline \multicolumn{2}{|c|}{ Characteristics } & \multirow{2}{*}{$\begin{array}{c}\text { Number (\%) } \\
62.4(41-82)\end{array}$} \\
\hline Age & Median (range) & \\
\hline \multicolumn{3}{|c|}{ Gender } \\
\hline & Male & 65 (75.6) \\
\hline & Female & $21(24.4)$ \\
\hline \multicolumn{3}{|l|}{ Race } \\
\hline & White & $64(74.4)$ \\
\hline & Black & $5(5.8)$ \\
\hline & Other & $17(19.7)$ \\
\hline \multicolumn{3}{|c|}{ ECOG PS } \\
\hline & $0-1$ & $69(80.2)$ \\
\hline & $2-3$ & 17 (19.8) \\
\hline \multicolumn{3}{|c|}{ Histology } \\
\hline & $\mathrm{ADC}$ & $27(31.4)$ \\
\hline & LCC & $10(11.6)$ \\
\hline & SCC & $42(48.8)$ \\
\hline & NSCLC nos* & $7(8.1)$ \\
\hline \multicolumn{3}{|c|}{ Clinical stage } \\
\hline & I (recurrent) & $4(4.6)$ \\
\hline & II (recurrent) & $8(9.3)$ \\
\hline & III & $43(50)$ \\
\hline & IV & $31(36)$ \\
\hline \multicolumn{3}{|c|}{ First-line treatment } \\
\hline & Surgery & $8(9.3)$ \\
\hline & Radiotherapy & $50(58.1)$ \\
\hline & Chemotherapy & 72 (83.7) \\
\hline
\end{tabular}

*No otherwise specified NSCLC. 
male patients, white race, PS 0-1, squamous cell carcinoma histology, and clinical stage III-IV. Eighty-three \% of included patients received platinum-based chemotherapy and 58\% radiotherapy as first-line treatment according NSCLC treatment guidelines recommendations.

In the ITT efficacy, analysis the median overall survival time was 8.96 months for vaccinated patients. The survival rates at 12 and 24 months were $42.8 \%$ y $28.0 \%$ respectively (Figure 1 ).

In order to assess the clinical benefit in patients that completed the induction phase, we performed a per protocol analysis selecting those with five or more doses of racotumomab-alum vaccine. In this group, the median OS was 12.1 months compared to 2.06 months in patients with less than five immunizations. There is a significant clinical benefit in terms of OS $(\mathrm{p}=0.000)$ for patients that completed the induction phase of treatment schedule (Figure 2).

Two hundred and fifteen adverse events were recorded in vaccinated patients. The most frequently described adverse events were injection-site reaction (23.2\%), bone pain (7.9\%), cough (5.6\%) and asthenia (5.6\%) (Table 2). Most of them were classified as mild (69.76\%) or moderate $(10.69 \%)$ according severity grades of Common

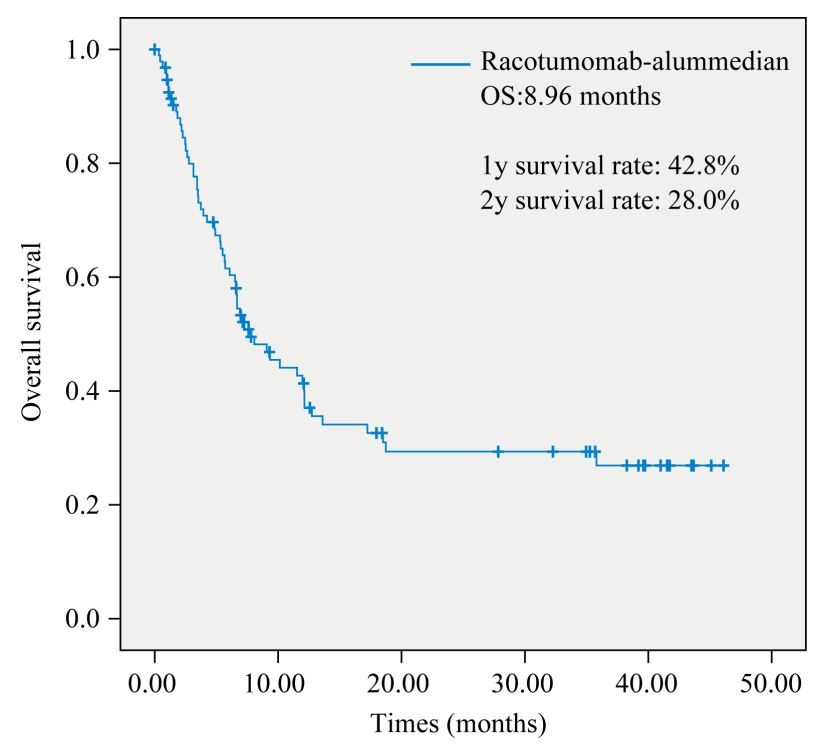

Figure 1. Intent to treat overall survival (OS) in vaccinated patients.

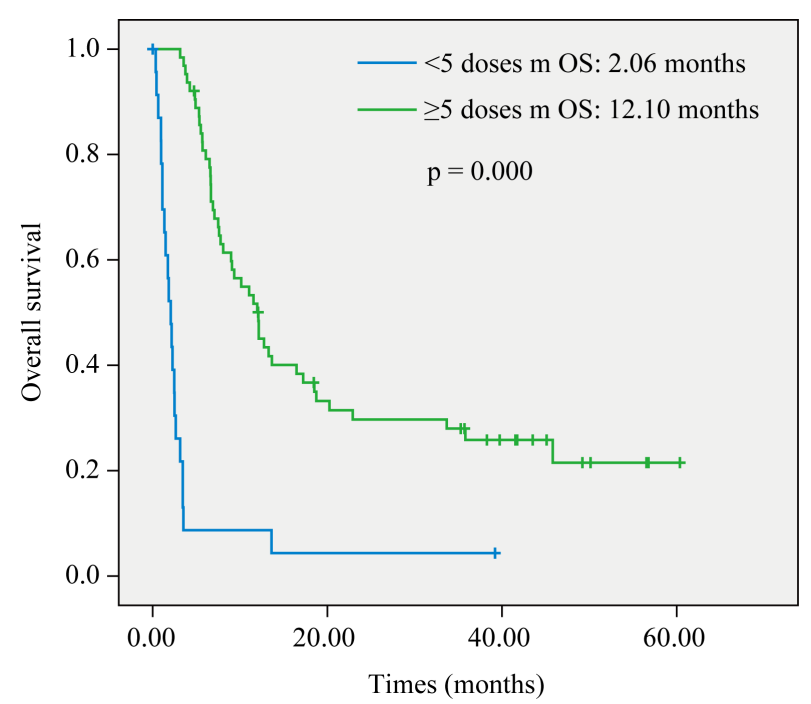

Figure 2. Per protocol overall survival (OS) in vaccinated patients. 
Terminology Criteria for Adverse Events version 3 (CTCAEv3). Only 19.4\% of all reported events, regardless causality, was grade 3 - 4 (Table 3). Only 83 adverse events were classified as related to racotumomab-alum vaccine by clinical investigators. All of them were grade 1 according CTCAEv3. There were not deaths related to the study treatment.

\section{Discussion}

In our study, advanced NSCLC patients treated with racotumomab-alum as second-line therapy achieved a median survival time of 8.96 months compared with the results of other drugs in this setting. A median survival time from 5 to 8 months has been reported with registered second-line treatment options [6]-[8]. This benefit in OS is greater if the patient can complete the induction phase of vaccine therapy, because it is necessary time and frequent re-immunizations to develop an efficient antitumoral immune response. In the per protocol analysis those patients reached a median OS of 12 months, similar to the OS reported with maintenance therapy in nonprogressor patients [9].

Other vaccines have been tested in NSCLC patients without encouraging results. Recently, two cancer vaccines have failed increasing overall survival in phase III clinical trials: Belagenpumatucel-L (Lucanix) and L-BLP25 (Stimuvax) [20] [21]. Otherwise there are preliminary results from a phase III trial of CIMAvaxEGF that suggest an improvement in overall survival of vaccinated patients [22].

Racotumomab-alum treatment is safe. All treatment-related adverse events are mild and there are no deaths related to vaccine. This benefit in terms of safety could be an advantage compared with chemotherapeutic agents, since the vaccine could be administered for long treatment periods in order to control NSCLC as a chronic disease.

\begin{tabular}{ccc|}
\hline \multicolumn{3}{c}{ Table 2. Most frequent adverse events in vaccinated patients. } \\
\hline Adverse events & Number & Percentage \\
\hline Injection-site reaction & 50 & 23.2 \\
Bone pain & 17 & 7.9 \\
Cough & 12 & 5.6 \\
Asthenia & 12 & 5.6 \\
Dispnea & 10 & 4.6 \\
Fever & 9 & 4.2 \\
Anorexia & 8 & 3.7 \\
Haemoptisis & 5 & 2.3 \\
Headache & 4 & 1.9 \\
Myalgia & 3 & 1.4 \\
Rash & 2 & 0.9 \\
Vomiting & 2 & 0.9 \\
\hline
\end{tabular}

Table 3. Severity of adverse events in vaccinated patients.

\begin{tabular}{ccc}
\hline Severity & Number of AE & Percentage (\%) \\
\hline Mild & 150 & 69.76 \\
Moderate & 23 & 10.69 \\
Severe & 16 & 7.44 \\
Life-threating & 26 & 12.09 \\
Total & 215 & 100 \\
\hline
\end{tabular}


Even when our results come from an expanded access program without a control group, we think that this vaccine could be a treatment option for patients with progressive disease. This hypothesis will be confirmed with the result of RANIDO trial where racotumomab-alum is being compared with docetaxel in this scenario.

\section{References}

[1] American Cancer Society (2013) Cancer Facts \& Figures 2013. American Cancer Society, Atlanta.

[2] Public Health Ministry and National Medical Records (2013) Health Statistics Yearbook 2012. MINSAP, La Habana.

[3] Finkelstein, D.M., Ettinger, D.S. and Ruckdeschel, J.C. (1986) Long-Term Survivors in Metastatic Non-Small-Cell Lung Cancer: An Eastern Cooperative Oncology Group Study. Journal of Clinical Oncology, 4, 702-709.

[4] Howlader, N., Noone, A., Krapcho, M., et al. (2012) SEER Cancer Statistics Review, 1975-2009 (Vintage 2009 Populations) Based on November 2011 SEER Data Submission. National Cancer Institute, Bethesda.

[5] Grossi, F., Gridelli, C., Aita, M. and De Marinis, F. (2008) Identifying an Optimum Treatment Strategy for Patients with Advanced Non-Small Cell Lung Cancer. Critical Reviews in Oncology/Hematology, 67, 16-26. http://dx.doi.org/10.1016/j.critrevonc.2007.12.002

[6] Shepherd, F.A., Dancey, J., Ram Lau, R., Mattson, K., Gralla, R., O’Rouke, M., et al. (2000) Prospective Randomized Trial of Docetaxel versus Best Supportive Care in Patients with Non-Small Cell Lung Cancer Previously Treated with Platinum-Based Chemotherapy. Journal of Clinical Oncology, 18, 2095-2103.

[7] Hanna, N., Shepherd, F.A., Fossella, F.V., Pereira, J.R., De Marinis, F., von Pawel, J., et al. (2004) Randomized Phase III Trial of Pemetrexed versus Docetaxel in Patients with Non-Small Cell Lung Cancer Previously Treated with Chemotherapy. Journal of Clinical Oncology, 22, 1589-1597. http://dx.doi.org/10.1200/JCO.2004.08.163

[8] Shepherd, F.A., Rodriguez Pereira, J., Ciuleanu, T., Tan, E.H., Hirsh, V., Thongprasert, S., et al. (2005) Erlotinib in Previously Treated Non-Small Cell Lung Cancer. New England Journal of Medicine, 353, 123-132. http://dx.doi.org/10.1056/NEJMoa050753

[9] Gridelli, C., de Marinis, F., Di Maio, M., Ardizzoni, A., Belani, C., Cappuzzo, F., et al. (2012) Maintenance Treatment of Advanced Non-Small Cell Lung Cancer: Results of an International Expert Panel Meeting of the Italian Association of Thoracic Oncology. Lung Cancer, 76, 269-279. http://dx.doi.org/10.1016/j.lungcan.2011.12.011

[10] Irie, A. and Suzuki, A. (1998) CMP-Neu-Acetylneuraminic Acis Hydroxilase Is Exclusively Inactive in Humans. Biochemical and Biophysical Research Communications, 248, 330-333. http://dx.doi.org/10.1006/bbrc.1998.8946

[11] Chou, H.H., Takematsu, H., Díaz, S., Iber, J., Nickerson, E., Wright, K.L., et al. (1998) A Mutation in Human CMPSialic Acid Hydroxylase Occurred after the Homo-Pan Divergence. Proceedings of the National Academy of Sciences of the United States of America, 95, 11751-11756. http://dx.doi.org/10.1073/pnas.95.20.11751

[12] Hayashi, N., Chiba, H., Kuronuma, S., Go, S., Hasegawa, Y., Takahashi, M., et al. (2013) Detection of N-Glycolyated Gangliosides in Non-Small-Cell Lung Cancer Using GMR8 Monoclonal Antibody. Cancer Science, 104, 43-47. http://dx.doi.org/10.1111/cas.12027

[13] Hernández, A.M., Rodríguez, M., López-Requena, A., Beausoleil, I., Pérez, R. and Vázquez, A.M. (2005) Generation of Anti-Neu-Glycolyl-Ganglioside Antibodies by Immunization with an Anti-Idiotype Monoclonal Antibody: A Selfversus Non-Self-Matter. Immunobiology, 210, 11-21. http://dx.doi.org/10.1016/j.imbio.2005.02.002

[14] Alfonso, M., Diaz, A., Hernández, A.M., Pérez, A., Rodríguez, E., Bitton, R.J., et al. (2002) An Anti-Diotype Vaccine Elicits a Specific Response to N-Glycolyl Sialic Acid Residues of Glycoconjugates in Melanoma Patients. Journal of Immunology, 168, 2523-2529. http://dx.doi.org/10.4049/jimmunol.168.5.2523

[15] Díaz, A., Alfonso, M., Alonso, R., Saúrez, G., Troce, M., Catalá, M., et al. (2003) Immune Responses in Breast Cancer Patients Immunized with an Anti-Idiotype Antibody Mimicking NeuGc-Containing Gangliosides. Clinical Immunology, 107, 80-89. http://dx.doi.org/10.1016/S1521-6616(03)00036-6

[16] Guthmann, M.D., Castro, M.A., Cinat, G., Venier, C., Koliren, L., Bitton, R.J., et al. (2006) Cellular and Humoral Immune Response to N-Glycolyl-GM3 Elicited by Prolonged Immunotherapy with an Anti-Idiotypic Vaccine in High Risk and Metastatic Breast Cancer Patients. Journal of Immunotherapy, 29, 215-223. http://dx.doi.org/10.1097/01.cji.0000188502.11348.34

[17] Neninger, E., Diaz, R., de la Torre, A., Rives, R., Díaz, A. and Saúrez, G. (2007) Active Immunotherapy with $1 E 10$ MAb Anti-Idiotype Vaccine in Patients with Small Cell Lung Cancer. Report of a Phase I Trial. Cancer Biology \& Therapy, 6, e1-e6. http://dx.doi.org/10.4161/cbt.6.2.3574

[18] Alfonso, S., Díaz, R., De la Torre, A., Santiesteban, E., Aguirre, F., Pérez, K., et al. (2007) 1E10 MAb Anti-Idiotypic Vaccine in Non-Small Cell Lung Cancer: Experience in Stage IIIB and IV Patients. Cancer Biology \& Therapy, 6, 1-6. http://dx.doi.org/10.4161/cbt.6.12.5000

[19] Alfonso, S., Valdés-Zayas, A., Santiesteban, E., Flores, I., Areces, F., Hernández, M., et al. (2014) A Randomized, 
Multicenter, Placebo-Controlled Clinical Trial of Racotumomab-Alum Vaccine as Switch Maintenance Therapy in Advanced Non-Small Cell Lung Cancer. Clinical Cancer Research, in Press. http://dx.doi.org/10.1158/1078-0432.CCR-13-1674

[20] Giaccone, B.L., Nemunaitis, N., Juhasz, E., Ram Lau, R., van den Heuvel, M.M., et al. (2013) A Phase III Study of Belagenpumatucel-L Therapeutic Tumor Cell Vaccine for Non-Small Cell Lung Cancer (NSCLC). 17 European Cancer Congress 2013 Presidential Session I: Best and Late Breaking Abstracts, Abs 2.

[21] Butts, C.A., Socinski, M.A., Mitchell, P., Thatcher, N., Havel, L., Krzakowski, M.J., et al. (2013) START: A Phase III Study of L-BLP25 Cancer Immunotherapy for Unresectable Stage III Non-Small Cell Lung Cancer. Journal of Clinical Oncology, 31, Abstract No. 7500).

[22] Crombet, T., Acosta, S., Amador, R., Mendoza, S., Santiesteban, E., Rodriguez, C., et al. (2012) EGF-Based Cancer Vaccine for Advanced NSCLC: Results from a Phase III Trial. Journal of Clinical Oncology, 30, Abstract No. 2527. 
Scientific Research Publishing (SCIRP) is one of the largest Open Access journal publishers. It is currently publishing more than 200 open access, online, peer-reviewed journals covering a wide range of academic disciplines. SCIRP serves the worldwide academic communities and contributes to the progress and application of science with its publication.

Other selected journals from SCIRP are listed as below. Submit your manuscript to us via either submit@scirp.org or Online Submission Portal.
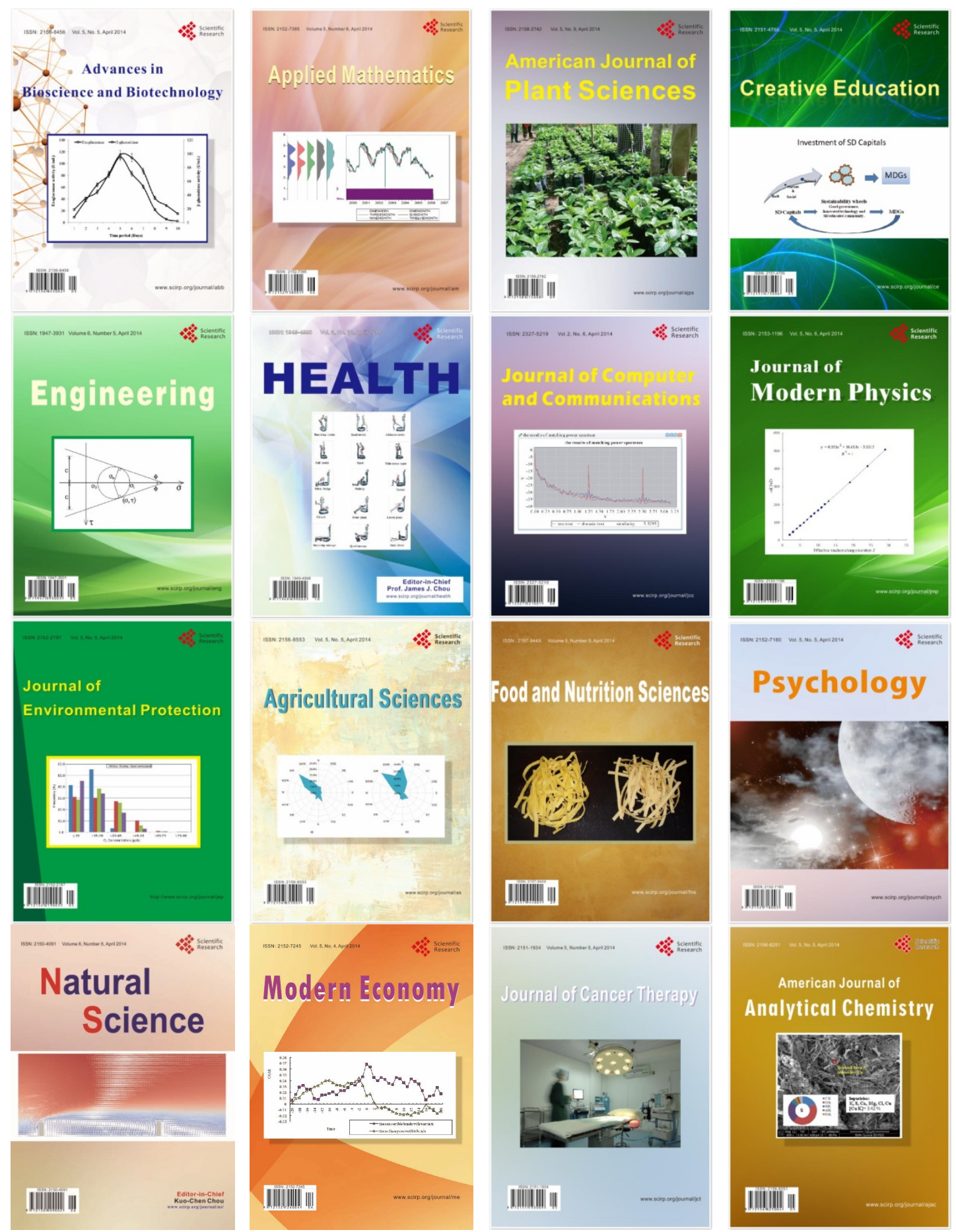